\title{
Internal structure of nanoporous TiO2 I polyion thin films prepared by layer-by-layer deposition
}

\author{
R. Kniprath, S. Duhm, H. Glowatzki, N. Koch, S. Rogaschewski, J. P. Rabe, S. Kirstein
}

Institute of Physics, Humboldt University of Berlin, 12489 Berlin, Germany

\section{Supporting Information}

Scanning electron micrographs (SEM) for samples of type B (TiO2 particles and PSS) and type C (TiO2 particles and PDAC) are presented. The films are prepared under different salt conditions of the polyelectrolyte solution and for different molecular weight of the polyelectrolytes. The images demonstrate that these parameter do not have any influence on the film morphology. 



Scanning electron micrographs for samples of type $\mathrm{C}\left(\mathrm{TiO}_{2}\right.$ particles and PDAC). The images provide a successive zoom in from left to the right, where the scale is $120 \times 80 \mu \mathrm{m}$ (left) and $6 \times 4 \mu \mathrm{m}$ (right). The films are prepared under different salt conditions of the PDAC solution and for different molecular weights of PDAC as follows:
a) $1 \mathrm{M} \mathrm{NaCl}, \mathrm{MW}=400000-500000$
b) $0 \mathrm{M} \mathrm{NaCl}, \mathrm{MW}=400000-500000$
c) $0 \mathrm{M} \mathrm{NaCl}, \mathrm{MW}<100000$ 



Scanning electron micrographs for samples of type $\mathrm{B}\left(\mathrm{TiO}_{2}\right.$ particles and $\left.\mathrm{PSS}\right)$. The images provide a successive zoom in from left to the right, where the scale is $120 \times 80 \mu \mathrm{m}$ (left) and $6 \times 4 \mu \mathrm{m}$ (right). The films are prepared under different salt conditions of the PSS solution and for different molecular weights of PSS as follows:

d) $1 \mathrm{M} \mathrm{NaCl}, \mathrm{MW}=70000$

e) $0 \mathrm{M} \mathrm{NaCl}, \mathrm{MW}=70000$

f) $0 \mathrm{M} \mathrm{NaCl}, \mathrm{MW}=1000000$ 